\title{
Cal Poly Wins Again: Bank of America/Merrill Lynch Low Income Housing Challange
}

\author{
Andrew Levin \\ Senior, BCRP, Cal Poly.
}

In 2013, for the third time in a row, a Cal Poly team took first place in the Bank of America/Merrill Lynch Low Income Housing Challenge. Andrew Levin, one of the undergraduates in the winning team, writes about this interdisciplinary opportunity to contribute to one of America's pressing problems.

C al Poly has a long history of competing in the Bank of America Low Income Housing Challenge, and 2013 is the third consecutive year that a team from Cal Poly took first place against other highly ranked colleges in California. The Bank of America Low Income Housing Challenge is an annual interdisciplinary competition open to both undergraduate and graduate students that provides the unique opportunity for collaboration between different majors to design sustainable affordable housing.

Conceived in 1992 by the Community Development Banking Group of Bank of America Merrill Lynch, the competition provides students a rare opportunity to be immersed into the field of affordable housing development on a professional level, and can yield valuable insight into the financial, legal, and design challenges associated with providing sustainable affordable housing in California.

The competition lasts two quarters, and culminates in Spring quarter when teams from colleges around California meet at the Bank of America headquarters in San Francisco where they present their project to a panel of professional architects, planners, and financiers who are experts in the field of affordable housing.

\section{The Competition Process}

The first half of the competition takes place during Winter Quarter at Cal Poly, when interdisciplinary student teams are formed and then briefed on the background and current state of affordable housing in California. Groups must then find a "developer partner;" a developer with either experience or interest in affordable housing that can mentor and guide the group using their real-world experience in finance and design as a foundation for the group's hypothetical project. Developer partners and student groups either work together to find a site for the project or use one pre-selected by the developer.

Once a site has been selected, teams begin researching green-building techniques, design concepts, case studies, affordability needs analyses, and public outreach plans so that project begins to take shape on a conceptual level. By the end of Winter Quarter, teams submit a ten page conceptual proposal that includes basic financial information, zoning information, design schematics and site layouts. The competition's panel of expert judges then reviews this document and voices any feedback or concerns that they have about that particular project as well as outlining particular aspects of the project they would like teams to emphasize in the final proposal.

With the beginning of Spring Quarter teams use the feedback from the panel of judges to refine and improve their projects, and the final proposals begin to take shape. Generally during this time student teams will visit their site at least once to get a feel for the site's context and physical features that may not have been obvious during the research process. Site visits help teams create a proposal that speaks to the character and needs of their city and is best suited for their particular site.

As Spring Quarter draws to a close, the competition truly is defined by the interdisciplinary nature of the teams. Students from different areas of study learn to utilize the strengths of each other's fields and work cooperatively in ways that are otherwise unavailable in a normal classroom environment. Business and Construction Management majors, who are responsible for creating the development timeline and managing the finances of the team, learn about the design process and how finances can be integrated into that process to more easily create a cost-efficient design. Similarly, architects and planners can learn from finance majors about keeping costs down while ultimately creating a sustainable and attractive final product and a place where people would be proud to live.

Perhaps the most valuable aspect of the competition is the experience gained simply by learning from one another in a setting with professional expectations. Successful teams 
are composed of students who are willing to heed the expertise of their peers and professors and work together using the tools of effort and compromise to achieve a high quality and competitive final product.

\section{Cal Poly Teams in the 2013 Competition}

The continuous success of Cal Poly's teams in the LowIncome Housing Challenge reflects their ability to effectively analyze site conditions and community needs while developing sustainable, cost-efficient, and feasible design solutions. This year Cal Poly had three teams competing, supervised by CRP professor Hemalata Dandekar and Menka Sethi from the College of Business. Their proposals were as follows.

\section{Terra Housing Studio}

\section{Winner of the 2013 Low-Income Housing Challenge}

Graduate students Brian Harrington (CRP) and Smita Naik (Architecture), and undergraduate students Cameron Anvari (Business) and Emily Gerger, Tim McGarvy, Nuri Cho and Andrew Levins (CRP).

The Terra Housing Studio team prepared an affordable housing project proposal for Cambria, a small coastal town north of San Luis Obispo, backed by developer partner People's Self-Help Housing. Cambria's economy relies heavily on tourism that requires low-wage service workers. Due to the high price of housing these workers are forced to live in more affordable areas of the county or to crowd multiple families in single-family homes. Among the several factors that reflect on housing costs is Cambria's location by the sea, a moratorium on new development because of the water shortage, and the lack of diverse housing types.

The Cambria Pines is an affordable forty-unit apartment complex proposed by the Terra Housing Studio to meet these needs. Based on community input, its financially realistic and sustainable design integrates seamlessly into the community. Making use of a series of green-building techniques and environmental-friendly urban design solutions, the project reduces the overall environmental footprint and will help tenants save money. These techniques include simple appropriate site design, a laundry-to-landscape greywater recycling system to irrigate the community gardens, integrating rain barrels for landscape irrigation, and an architecture design that provides maximum solar efficiency for passive heating and cooling. Besides reducing day-to-day costs the green solutions encourage community environmental awareness and promote a more sustainable life. A trail and bike path runs through Cambria Pines, providing for interior connectivity and linking it to Cambria's downtown and the middle school.

During the research process, the team conducted outreach with community organizations, local leaders and other stakeholders, such as the Santa Lucia Middle School. The participatory approach led to the inclusion of a community center in the proposal, including a free daycare for children under the age of five living in the complex, as well as multipurpose rooms for services to the Cambria community at large, such as basic medical and dental, educational programs promoting healthy lifestyles, parenting education, mental health services, GED and ESL classes, relationship/marriage education, and emergency crisis intervention. Space for a LINK family advocate will also be provided for free counseling and support services to families of the middle school besides families residing in Cambria Pines.

\section{Cal Poly Affordable Communities}

Kelly Cheung, Dianne Acevedo and Malia Fa'asua (CRP), Raymond Chen (Finance, minor in Statistics), David Nguyen (Construction Management).

The Cal Poly Affordable Communities (CPAC) interdisciplinary team worked closely with People's Self-Help Housing, the nonprofit development partner, to contribute towards responding to a critical demand for affordable units in the City

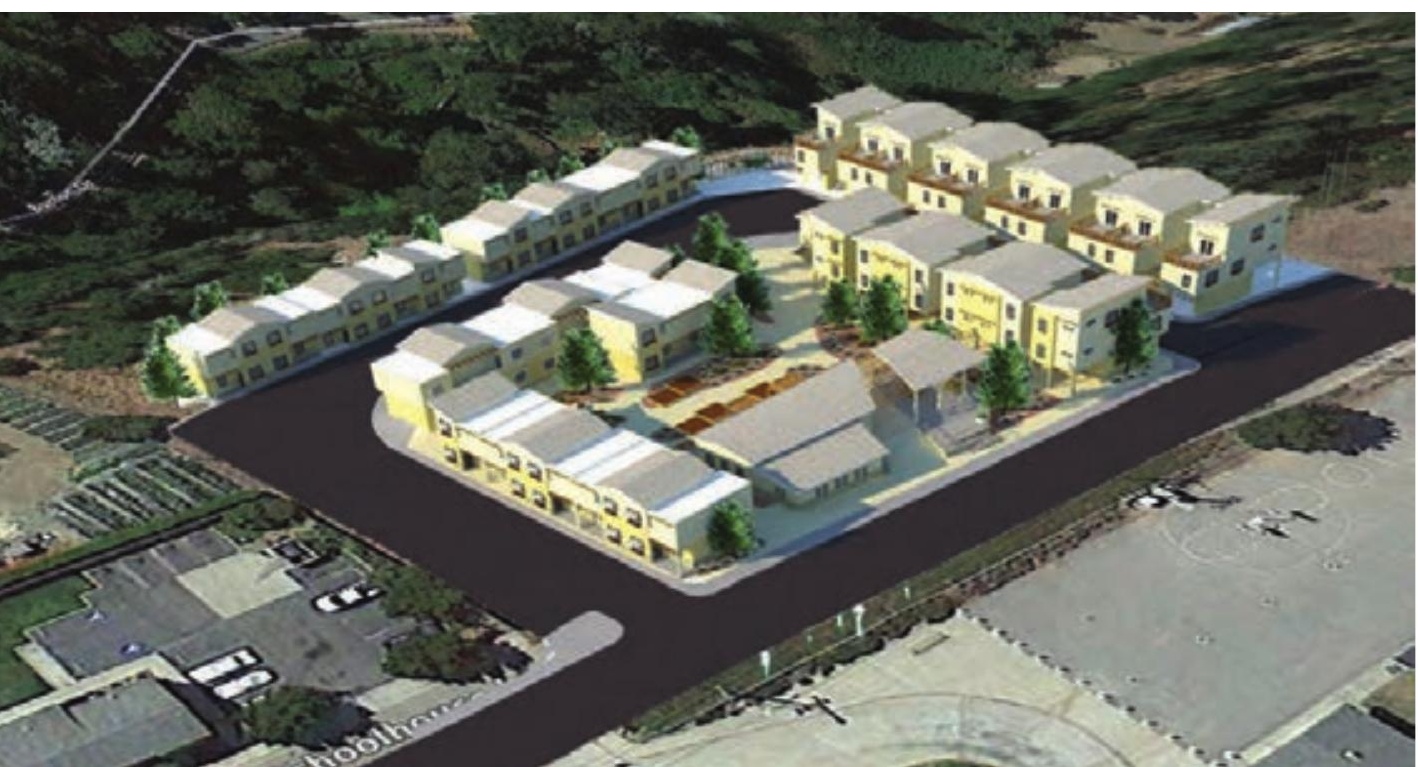

Figure 1: The winning entry, Cambria Pines in Cambria. 
